\title{
Poesía de puertas para adentro: una reconstrucción de la resistencia'
}

\author{
RAQUEL LANSEROS SÁNCHEZ \\ Universidad de Zaragoza \\ España \\ raqlanseros@yahoo.es
}

Poetry During Lockdown - Reconstruction of the Resistance

(Recibido: 28/04/202O; aceptado:05/05/2020)

Resumen. El presente artículo trata de ser un conciso homenaje a la literatura, que acompaña a los seres humanos desde el inicio de los tiempos, transformando la vida en algo mucho más rico, consistente y duradero. La energía de la poesía se funde con las circunstancias históricas y hace emerger la palabra solidaria en los momentos difíciles, como la pandemia global de coronavirus, que ha obligado a convertir los actos culturales presenciales en destellos fabricados de puertas para adentro que se proyectan al mundo. Los poetas no se detienen y siguen tendiendo su palabra como un asidero común frente a la adversidad.

Palabras clave: literatura; poesía; Internet; pandemia; redes sociales.
Abstract. This article attempts a concise tribute to literature, which has accompanied human beings since the beginning of time, transforming life into something much richer, more consistent and everlasting. The energy of poetry merges with historical circumstances and makes the solidarity word emerge in difficult moments, such as the global coronavirus pandemic, which has forced the conversion of faceto-face cultural acts into glimpses manufactured indoors to be projected into the world. Poets do not stop but continue to spread their word as a common support in the face of adversity.

Keywords: literature; poetry; Internet; pandemic; social media.

\footnotetext{
I'Para citar este artículo: Lanseros Sánchez, Raquel (2020). Poesía de puertas para adentro: una reconstrucción de la resistencia. Alabe 22 . [www.revistaalabe.com]

DOI: IO.I5645/Alabe2O2O.22.II
} 
La poesía, por su esencia volátil y poco aprensible para las relaciones utilitarias que rigen los mecanismos del poder y del mercado, ha constituido siempre un bastión de resistencia. Se trata de una resistencia que rebasa el territorio de lo simbólico y se instala en lo sensible, lo estético, lo ético, lo cultural, lo lingüístico, lo histórico, lo deontológico y lo moral. En los últimos tiempos, hemos vivido una paulatina fragmentación de los tradicionales paradigmas culturales que permitían una cierta conciliación con las realidades cotidianas. Existe una creciente brecha entre tecnología y naturaleza, entre producción y conservación del medio ambiente. Esto crea un estado de crisis permanente que tiene su reflejo lingüístico, social, político y económico. Las utopías libertarias han ido progresivamente haciéndose a un lado ante el irrefrenable avance de megaurbes caóticas, masificadas, anónimas y repletas de habitantes solitarios y aislados. Por otro lado, la mentalidad dominante de supremacía del individualismo - un efecto frivolizado y narcisista del sometimiento del ser humano al gran capital- sobre la colectividad parece unánime e imposible de resquebrajar. Lo social y lo solidario se ven desplazados ante la lógica de la inmediatez, del espectáculo impactante y momentáneo (Fajardo Fajardo, I997, p.II6).

En este escenario se mueven los poetas de principios del siglo XXI, inmersos en un mundo globalizado e hiperconectado en el que todo parece tener fecha instantánea de caducidad y en el que la indagación veraz -como por definición es siempre la artística- se vuelve enojosa, en aras de un facilismo que denosta la paciencia, la perseverancia y el tesón, preceptivos en toda búsqueda del conocimiento que se precie. Y de pronto, llega 2O2O, un año de cifra sugerente que nos obliga a plantearnos que han pasado ya veinte años -ese tiempo que en términos gardelianos equivale a nada- desde el mítico 200O, con sus promesas futuristas y sus temores finmilenaristas, extremos ambos ya casi olvidados dos décadas después. Para sorpresa generalizada, el segundo quinto de siglo se estrena con uno de los grandes espantos seculares de la humanidad: una epidemia de alta ferocidad que en muy pocas semanas se transforma en tragedia global, siendo denominada oficialmente como pandemia por la Organización Mundial de la Salud. En cuestión de días, los ciudadanos del orbe occidental -particularmente Europa y Estados Unidos- ven tambalearse sus certidumbres preestablecidas, hasta el punto de abandonar forzosamente sus rutinas diarias para internarse en un confinamiento domiciliario cuyo grado de severidad ha variado según países y focos de infección, pero que de modo genérico ha interrumpido la existencia para instalarla en una tensa espera de apaciguamiento viral que los medios de comunicación apodan reiterativamente el pico de la curva.

La historia de nuestra especie está desgraciadamente salpicada de terribles plagas que en no pocos casos han supuesto finales imperiales y colapsos civilizatorios. En la memoria ancestral de todos nosotros está la peste negra, hasta la fecha la pandemia más devastadora de la Historia, que afectó a Eurasia y Europa a mediados del siglo XIV y dejó millones de fallecidos, al menos un tercio de los habitantes europeos en las estimaciones más optimistas. Aquella espeluznante catástrofe es el marco de una de las grandes obras literarias de nuestra cultura: El Decamerón, de Giovanni Boccaccio, protagonizado por los cuentos y leyendas que narran un grupo de diez jóvenes que han huido de la epidemia 
y se han refugiado en una villa a las afueras de Florencia. Las similitudes con nuestros días son numerosas y desconcertantes. La enfermedad, proveniente del este, llega primero a Italia y desde allí se expande a todo el continente europeo. La aterrorizada población siente el impulso de abandonar las ciudades y resguardarse en el campo. Las costumbres y modos de organización social imperantes son puestos en cuestión a causa de la peste: «Si queremos correr tras la salud, nos conviene encontrar el modo de organizarnos de tal manera que de aquello en lo que queremos encontrar deleite y reposo no se siga disgusto y escándalo» (Boccaccio, I989, p.43). Existen corrientes históricas que atribuyen a la peste negra la manifestación final de la crisis del feudalismo y el estímulo para la subsiguiente renovación que dio lugar al Renacimiento. En cualquier caso, es innegable que el sobrecogedor desastre supuso un punto de inflexión entre el mundo precedente y el posterior.

Casi siete siglos después, la enfermedad por coronavirus, Covid-I9, ha mostrado una virulencia desconocida desde hace al menos un siglo, cuando tras la Primera Guerra Mundial la pandemia de gripe de r9ı8 mató a millones de personas. En pleno siglo XXI, cuando la fe en la ciencia y en el desarrollo tecnológico habían hecho instalarse en gran parte de la sociedad una falsa creencia de invulnerabilidad, millones de personas se ven obligadas a un encierro en sus casas, con el fin de intentar contener el número de contagios para que los sistemas sanitarios puedan gestionar la presión sin desbordarse. Como consecuencia de la paralización de la actividad, grandes sectores económicos sufren una debacle. La humanidad, recluida y asustada, contiene el aliento. Como en el siglo XIV, las costumbres y modos de organización social imperantes son puestos en cuestión. Las prioridades personales y colectivas comienzan a modificarse. Se pone en cuestión el tipo de consumo, la contaminación ambiental, la especulación, la globalización que crea cadenas comerciales cada vez más alejadas de la producción local. Se pone de relieve la crisis climática, la sobreexplotación, la necesidad de reforzar las estructuras públicas de protección social. ¿Qué sucederá a partir de ahora? ¿Cómo será el mundo post-coronavirus? Nadie puede saberlo con certeza, aunque abundan las opiniones y los vaticinios.

Mientras tanto, en el mundo de la poesía proliferan las reacciones de todo tipo ante la situación. Los poetas se vuelcan en las nuevas tecnologías y las redes sociales para organizarse y crear plataformas de difusión. Desde que se establece el estado de alarma en España, se multiplican los gestos participativos con el fin de intentar poner la poesía a favor de la resistencia. Se trata de una reacción cultural, pero también cívica, los foros virtuales son un hervidero de versos, de anhelos, de ideas y reflexiones. Las iniciativas son muy variadas, desde particulares hasta institucionales, desde individuales hasta grupales, desde espontáneas hasta planificadas. La presencia se sustituye por la virtualidad, la poesía tiene lugar de puertas para adentro pero se proyecta hacia el mundo, Internet se convierte en el foro poético global. Son tantas las participaciones y proyectos que se hace imposible mencionar todos, pero resulta interesante repasar unos pocos desde aquí, para arrojar una idea de la vitalidad con que la poesía española ha respondido al reto de la pandemia global y su obligatorio distanciamiento social. Uno de los primeros encuentros 
virtuales en surgir fue \#PoesíaEnTuSofá, coordinado por los poetas Elvira Sastre, Andrea Valbuena y Fran Barreno. Transmitido por Instagram, red social en la que se creó su propia página, con cerca de cincuenta mil seguidores, el encuentro contó con integrantes de la lírica nacional e internacional como Marwan, Luis Ramiro, Benjamín Prado, Sara Búho, Rupi Kaur, Ben Clark, Luna Miguel, Alexis Díaz Pimienta o Ángelo Néstore, además de grandes nombres del mundo de la canción, el cine, el teatro o la televisión. También en Instagram, encontramos la cuenta Inversos, una idea del poeta Jota Santatecla con la ayuda de la agencia de publicidad Grupoidex, que ha creado una cadena de poesía que acerca sensaciones directamente relacionadas con la cuarentena, a la que ya se han sumado Carlos Catena, Alba Flores, Jorge Villalobos o Nerea Delgado, entre otros muchos. Como curiosidad, cabe destacar que todas estas creaciones nacidas a causa del confinamiento se recopilarán en un libro una vez regrese la ansiada normalidad. También los periódicos y las revistas se han sumado a esta avalancha de poesía que trata de contrarrestar la soledad y el aislamiento. El 20 de marzo de 2020 la portada de el suplemento cultural de El Mundo, ElCultural, llevaba por título "Poemas para una cuarentena", con versos inéditos de Rosa Berbel, Luisa Castro, Ben Clark, Antonio Colinas, Ariadna G. García, Luis García Montero, J. A. González Iglesias, Karmelo C. Iribarren, Raquel Lanseros, Chantal Maillard, Elvira Sastre y Manuel Vilas. El mismo periódico, El Mundo, publicaba el 7 de abril en exclusiva para sus lectores poemas sobre la pandemia de coronavirus, firmados por Felipe Benítez Reyes, Ada Salas, Manuel Vilas, Ana Merino, Lorenzo Oliván, Mariano Peyrou, Joaquín Pérez Azaústre, Marwan y Xaime Martínez. Zéjel, revista de arte, literatura y pensamiento, ha organizado desde su cuenta de Instagram un recital online titulado "La palabra que contamina”, consistente en la publicación de vídeopoemas grabados por diferentes poetas, como Gema Palacios, Carla Martínez Nyman, Alejandro Vargas o Javier Calderón, entre otros. En Twitter, una cuenta llamada Poeta de guàrdia publica diariamente un vídeopoema recitado y escrito expresamente para la ocasión. Han participado, entre muchos otros, Víctor Bonet, David Caño, Núria Martínez Vernis, Josep Pedrals o Biel Mesquida. También por esta red social han circulado hashtags como \#PoesiaenQuarentena, al que se han sumado cientos de personas con sus poemas. Como hemos mencionado anteriormente, han sido muchas también las instituciones que han contribuido a la difusión de la poesía durante los días de cuarentena. Desde el Instituto Cervantes, por ejemplo, se ha puesto en marcha una campaña de reconocimiento a las librerías bajo el lema \#LaLibertadEsUnaLibrería, que es precisamente un verso del Premio Cervantes 20I9, el poeta Joan Margarit. En ella han participado agentes culturales de todos los ámbitos: escritores, editores, libreros, políticos, intelectuales, críticos, gestores culturales y, por supuesto, también numerosos poetas. Desde la Fundación de los Ferrocarriles Españoles se ha lanzado una propuesta en sus sitios web y en sus diferentes redes sociales, donde se puede encontrar poesía y cuento en tiempos de confinamiento, en las voces de sus propios autores. Ganadores de los Premios del Tren "Antonio Machado" de Poesía y Cuento, organizado por la Fundación, leen fragmentos de las obras por las que recibieron el primer premio del certamen. Asimismo, el Ayuntamiento de Alcalá 
de Henares y la Universidad de Alcalá han puesto en marcha una campaña para festejar el Día del Libro titulada \#CervantesEnAlcalá, ya que las circunstancias sanitarias impidieron el acto de entrega del Premio Cervantes. A través de esta iniciativa, miembros de la comunidad cultural, gestores, escritores y numerosos poetas, comparten sus palabras de homenaje a la literatura, sus extractos de obras literarias o sus poemas. Casa Mediterráneo, dentro de su programación a distancia diseñada para este periodo, ha organizado un ciclo titulado "Poemas del Mediterráneo", en el cual reconocidos poetas de España y de diversos países de la cuenca mediterránea recitan uno de sus poemas en formato vídeo. Los vídeopoemas de autores como Rafael Soler, Juan Carlos Mestre, Benjamín Prado, Rosa Cuadrado, Ángeles Mora, Abderrahman El Fathi, Raquel Lanseros o Rocío Acebal, entre otros, son retransmitidos por el canal de YouTube de Casa Mediterráneo y el resto de sus redes sociales. También la Casa de América ha desarrollado proyectos de recitales de poesía en formato grabado. Participan, entre otras, las poetas Gioconda Belli, Piedad Bonnet, Yolanda Pantin o Rosa Silverio. Por otro lado, se hace obligatorio mencionar un premio de poesía mítico en España, el Premio Adonáis, comprometido desde I943 con la promoción de nuevas voces de la poesía española, que, con el fin de hacer más llevadero el confinamiento, ha lanzado desde su cuenta de Twitter la campaña \#RecitaAdonais. Numerosos poetas que han publicado en la colección Adonáis recitan versos de cualquier otro poeta, siempre que éstos estén incluidos en cualquier libro publicado a su vez por la colección Adonáis, conformando así una ancha constelación de poetas de la casa, a la cual pertenecen muchos de los grandes nombres de la lírica española de los siglos XX y XXI. Por toda la geografía española se suceden los encuentros en formato virtual, algunos de ellos con una larga trayectoria presencial, como las Noches Poéticas en Bilbao. Fuera de nuestras fronteras, estas iniciativas también hacen presencia virtual, como el Incontro di Poesia "Respiro", promovido por la Accademia Mondiale della Poesia, que desde Verona busca inyectar oxígeno poético y anímico a los tiempos de incertidumbre. Numerosas aplicaciones sirven para reunir virtualmente a las personas alrededor de la poesía. A las ya mencionadas se unen Zoom, Google Meet, Facebook Watch, Hangouts, Skype y otras muchas. No importa la plataforma ni el formato, el mensaje oral o escrito, la inmediatez del directo o la permanencia de las grabaciones, fotografías o reproducciones de páginas de libros. Los poetas continúan trabajando en estos días de puertas para adentro, reconstruyendo la resistencia, recalcando la importancia de compartir la palabra en tiempos de pandemia. Nadie puede atreverse a aventurar cómo va a ser el mundo que vendrá, pero de una cosa podemos estar seguros: la poesía estará presente. 


\section{Referencias bibliográficas}

- Azancot N. (2O2O, 20 de marzo). Poemas para una cuarentena. Versos inéditos e inmunes para el Día de la Poesía. El Cultural de El Mundo, pp. 8-II.

- Boccaccio, G. (1989). El Decamerón. Barcelona: Plaza y Janés.

- Fajardo Fajardo C. (I997). La poesía: en la línea de resistencia. Cuadernos de Literatura, 3,6, II2-II8.

- Lucas. A. (2O2O, 7 de abril). Poesía en estado de alarma: 9 poemas inéditos sobre el coronavirus y el confinamiento. ElMundo, pp. $5^{2-54}$. 